\title{
Design and Experiment of Clamper Used in Antarctic Subglacial Bedrock Drilling
}

\author{
Pavel Talalay ${ }^{1}$, Xingchen $\mathrm{Li}^{1}$, Da Gong ${ }^{1,2, *}$, Xiaopeng Fan ${ }^{1}$, Nan Zhang ${ }^{1}$, Yang Yang ${ }^{1}$, \\ Yongwen Liu ${ }^{1}$, Yunchen Liu ${ }^{1}$, Ting Wang ${ }^{1}$ and Xiao $\mathrm{Li}^{1}$ \\ 1 Polar Research Center, Jilin University, Changchun 130026, China; talalay@jlu.edu.cn (P.T.); \\ lixc17@mails.jlu.edu.cn (X.L.); fxp@jlu.edu.cn (X.F.); znan@jlu.edu.cn (N.Z.); yangyang2014@jlu.edu.cn (Y.Y.); \\ liuan18@mails.jlu.edu.cn (Y.L.); wangliang18@mails.jlu.edu.cn (Y.L.); heaxe@163.com (T.W.); \\ lixiao17@mails.jlu.edu.cn (X.L.) \\ 2 College of Physics, Jilin University, Changchun 2699 Qianjin St., Changchun 130012, China \\ * Correspondence: gongd@jlu.edu.cn
}

Received: 6 May 2019; Accepted: 13 May 2019; Published: 17 May 2019

check for updates

\begin{abstract}
As a result of the severe natural environment with oxygen deficit in the Antarctic, using conventional manual work to screw and unscrew the drill pipe increases the labor intensity tremendously and causes an efficiency reduction. Therefore, it would be useful to design a clamper inside the drilling shelter, which could help to assemble and disassemble the ice core barrel with screw connection. This paper describes the design of and experiments with the clamper inside the movable drilling shelter. A related testing stand was also designed and built to experiment on relationships between the clamper motor current versus clamping torque and force. Through experimental data collation and calculation analysis, the following conclusions could be drawn: (1) according to the rotary ability of the Ice and Bedrock Electromechanical Drill (IBED) to calculate and determine the torque of clamper, the clamping torque required to provide by the clamper is $100 \mathrm{~N} \cdot \mathrm{m}$; (2) finite element simulation and analysis of the non-standard transmission chain showed that the mechanical reliability of the subparts; (3) the experimental results showed the range of the clamping force and clamping torque of the clamper. The clamping force and clamping torque increased with the increase of clamper DC motor current, presenting proportional linear relationships. The clamper can meet the clamping requirements of IBED for screwing, unscrewing, and clamping, which will be greatly helpful when it is tested in the field.
\end{abstract}

Keywords: clamper; polar drilling; Ice and Bedrock Electromechanical Drill; clamping torque; clamping force

\section{Introduction}

Drilling ice and subglacial bedrock in the Gamburtsev Mountains has valuable scientific significance in researching the formation of the Antarctic, Australia and South America, which also offers unique opportunities for examining processes acting at the bed of Gondwanaland [1-4]. Nevertheless, it is very difficult to retrieve a bedrock sample under the ice sheets and glaciers because of the terrible working conditions, such as the low temperature, lack of signal, dangerous crevasse road and limited logistical support, as well as some other effects caused by low temperature. Until now, only Russia and America had successfully retrieved a subglacial bedrock sample from beneath the Antarctic continent [5-7].

To drill through ice and subglacial bedrock, a new, modified version of the cable-suspended Ice and Bedrock Electromechanical Drill (IBED) series was designed and tested in the Polar Research Center at Jilin University. To overcome some current problems of this set of IBED, such as poor movability and the long preparation period, related affiliated equipment for drilling in ice and subglacial bedrock 
were also designed and integrated in a movable drilling shelter. Most operations could be finished inside the shelter. Figure 1 shows the 3D structure of the drilling shelter. The roundtrip of this kind of IBED is $2.5 \mathrm{~m}$, and therefore, penetrating at $1000 \mathrm{~m}$ thickness ice requires at least 400 roundtrips to lower down and lift up the drill, disassemble the ice core barrel, and take out the ice core from the core barrel. Considering the severe natural environment with the oxygen deficit and restricted working time in the Antarctic, using conventional manual work to screw and unscrew the drill pipe tremendously increases labor intensity and causes a low efficiency. It is necessary to design a clamper device inside the drilling shelter; after the whole drill body is lifted out from the borehole, the clamper can clamp the upper part of the drill tightly and then the screw-unscrew vehicle can unscrew out the core barrel from the drill body.

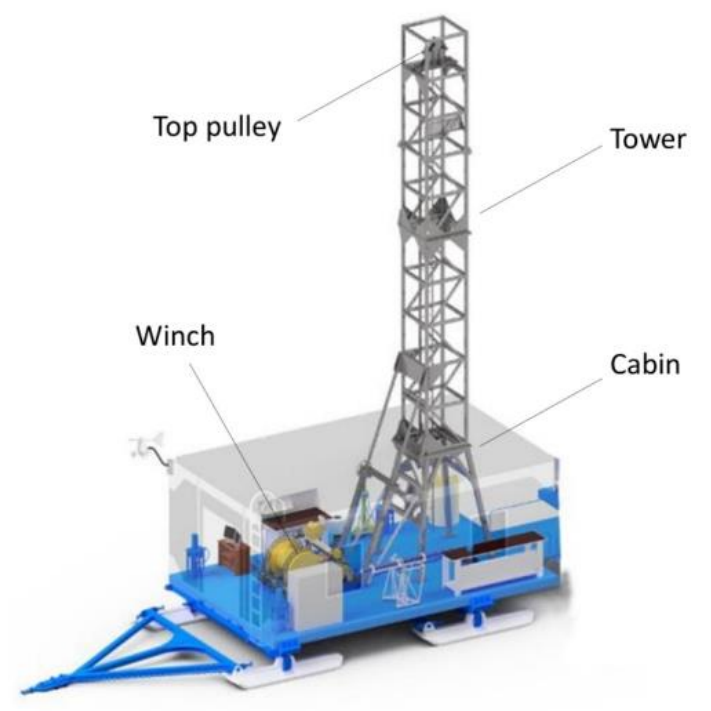

Figure 1. Structure of the movable polar drilling shelter.

This paper describes the design of and experiments with the drill clamper for the IBED series, based on the inside installation size requirements of the movable drilling shelter. It includes: (1) theoretical calculation on key parameters, including the clamping torque and clamping force; (2) finite element simulation and analysis on the stress distribution of non-standard transmission chain of the clamper structure, parameter optimization of subpart; (3) building a test stand to explore relationships between the motor current versus clamping force and torque, respectively.

\section{Concept Design of the Clamper Device}

Facilities in the drilling shelter for core barrel assembling and disassembling include the clamper device and the screw-unscrew vehicle. After the whole drill body is lifted into the drilling shelter, the clamper device can tightly hold the drill upper part, then the screw-unscrew vehicle can unscrew and remove the core barrel with core for subsequent operations. Total length of the IBED ice core drill is $7.5 \mathrm{~m}$ and the core barrel length is $2.5 \mathrm{~m}$, which means that the clamper should be installed more than $2.5 \mathrm{~m}$ above the shelter floor. Since the interior height from shelter floor to the ceiling is $2.8 \mathrm{~m}$ and the tower needs to be leveled down during then traction state, we chose the second steel beam as the clamper install position (Figure 2). Furthermore, for accurate screwing and unscrewing operations, the cylindrical axis of the two chuck jaws should be homocentric with the drill central axis. In this case, the clamper can execute its action easily and lower the risk of thread stuck caused by drill inclination. Figure 2 shows the clamper installation position in the drilling shelter. Once the clamper is installed, its mechanical assembly will be fixed in the drilling tower, and all pipe clamping and opening motions could be executed by one person through the customized control system. 


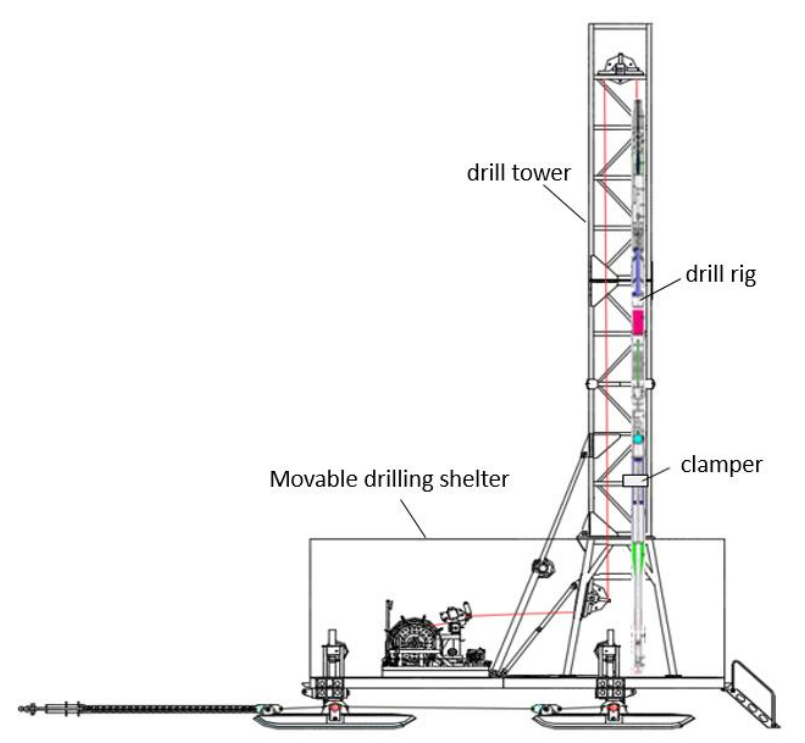

Figure 2. Diagram of the installation position of the clamper.

The interior section of the drilling tower is a steel beam square, with $1 \mathrm{~m} \times 1 \mathrm{~m}$ inside space. However, the top pulley takes the drill central axis away from the tower central line, which causes the distance from drill central line to the steel beam to be only $287 \mathrm{~mm}$. Therefore, the clamper should be compactly designed, and the distance from the chuck jaw cylindrical axis to the streel beam inside edge limited to no more than $287 \mathrm{~mm}$.

In view of the extremely natural environment in the Antarctic and the installation dimension requirement of the clamper inside the movable drilling shelter, the implementation scheme of the clamper was proposed, a double-arm clamper driven by motor through transmission chain; Figure 3 shows the working principle diagram of the clamper. When the clamper needs to clamp the drill, the motor rotates in a forward direction, and the torque is transmitted from the motor shaft to the lead screw through the gears. The positive and negative thread are designed on the left and right sides of the lead screw, respectively. Therefore, the forward rotating lead screw drives the two sliding nuts to move away from each other. Meanwhile, the moving nuts on each side turn the respective swing arms through the connecting rod, and finally the two chuck jaws close to each other to clamp the drill pipe. With the similar working principle, the clamper can release drill pipe from chuck jaws holding states by motor reverse rotation.

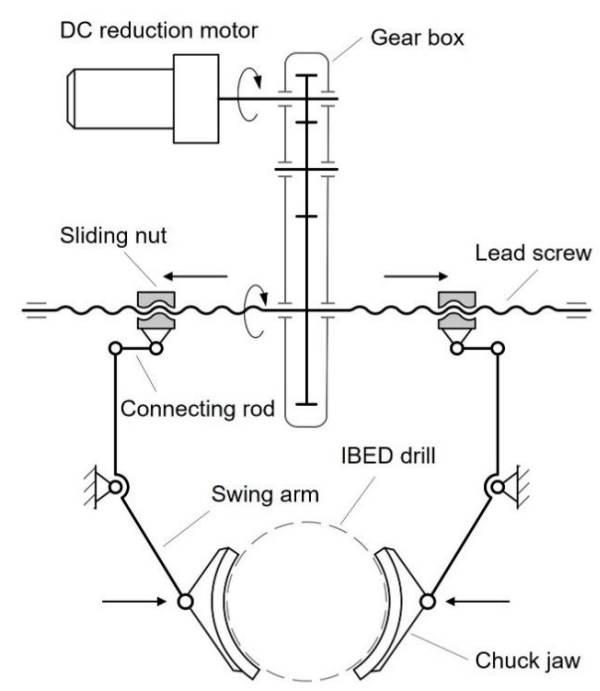

Figure 3. Working principle diagram of the clamper (pipe clamping process). 


\section{Calculations on Key Parameters of Clamper}

The clamping force and maximum clamping torque of the chuck jaw are the two key parameters on the design of the clamper. Therefore, it is necessary to analyze the technical requirements of the clamper before it is designed. According to the actual needs, the clamping force and the maximum clamping torque of the clamper need to be calculated to ensure reliability and effectiveness of the mechanism assembly.

\subsection{Clamping Torque of Clamper}

One of the clamper functions is to hold the drill upper parts tightly to ensure no relative rotation between them. Therefore, the clamper must be able to provide a clamping torque which is larger than the torque produced by drill unscrewing [8]:

$$
M_{c}>M_{u}
$$

where $M_{c}$ is the maximum clamping torque which the clamper could generate, $\mathrm{N} \cdot \mathrm{m}$; and $M_{u}$ is the torque required for unscrewing the drill, $\mathrm{N} \cdot \mathrm{m}$.

In the field ice drilling conditions, due to the complex situation in the borehole, there are many factors affecting the unscrewing torque and it is difficult to determine the true value. In conventional core drilling, the clamping torque of the clamper is always designed according to the maximum torque during drilling. Ideally, the unscrewing torque should be the same as the maximum output torque [8] of the drill:

$$
M_{u}=M_{d}
$$

where $M_{d}$ is the maximum output torque of the drill, $\mathrm{N} \cdot \mathrm{m}$.

The IBED is equipped a $3 \mathrm{~kW}$ AC $3 \times 380-\mathrm{V}$ submersible squirrel-cage induction motor of the Grundfos MS4000 type, which can provide maximum rotational speed of $2850 \mathrm{r} / \mathrm{min}$. In order to meet the requirements of rotational speed in different working conditions including ice drilling and subglacial bedrock drilling, two sets of gear reducers are designed: for ice drilling, the rotational speed of gear reducer is $100 \mathrm{r} / \mathrm{min}$; while for subglacial bedrock drilling, the rotational speed of gear reducer is $500 \mathrm{r} / \mathrm{min}$. From the practical experiences on ice core drillings, the required drill torque values approximately $10-20 \mathrm{~N} \cdot \mathrm{m}$, which is far less than the drilling torque required for bedrock drilling. Therefore, the maximum rotary torque of the drill can be determined according to the parameters of bedrock core drilling $[9,10]$. Drill output torque can be derived from the motor driving torque formula in electromechanics [11]:

$$
M_{d}=9550 \frac{P}{n_{d}} \eta
$$

where $P$ is the motor power, $\mathrm{kW} ; n_{d}$ is the rotational speed of drill bit, $\mathrm{r} / \mathrm{min}$; and $\eta$ is the transmission efficiency, which is assumed to be 0.85 .

Bring the above parameters into the Equation (3):

$$
M_{d}=9550 \times \frac{3}{500} \times 0.85=48.7 \mathrm{~N} \cdot \mathrm{m}
$$

Through combining Equations (1)-(4), it is found that the clamping torque required for the clamper should not be less than $48.7 \mathrm{~N} \cdot \mathrm{m}$.

However, the calculations above are available in ideal conditions, while in a real drilling process, drilling rigs are always very complicated in the hole. As soon as the drill gets stuck, the drilling torque of the drill bit would go up instantly. At that moment, the drilling torque will react to the threaded joint of the drill pipe and produce an additional screwing torque. Therefore, in a real drilling process, the unscrewing torque of the drill should refer to the maximum torque that may appear during drilling. 
In order to obtain the actual torque in core drilling, a testing stand for testing drill bits was designed in the Polar Research Center of Jilin University. The testing stand includes an XY- 1 type coring drill rig, a mud pump, a rock box and a drilling parameter detection and control system, and so on. Load, rotational speed, torque, and penetration rate can be measured in real time. The rock sample is fixed in the rock box. Experiment personnel controlled the XY-1 drill rig to drill and core the rock samples. The mud pump makes the drilling fluid circulate from rock box to setting tank, storage tank and drill internal space, and finally return back to the rock box. Meanwhile, rock chips are also pumped into the setting tank and deposit at the bottom [12-16]. The schematic diagram of the drilling parameters testing stand is shown in Figure 4.

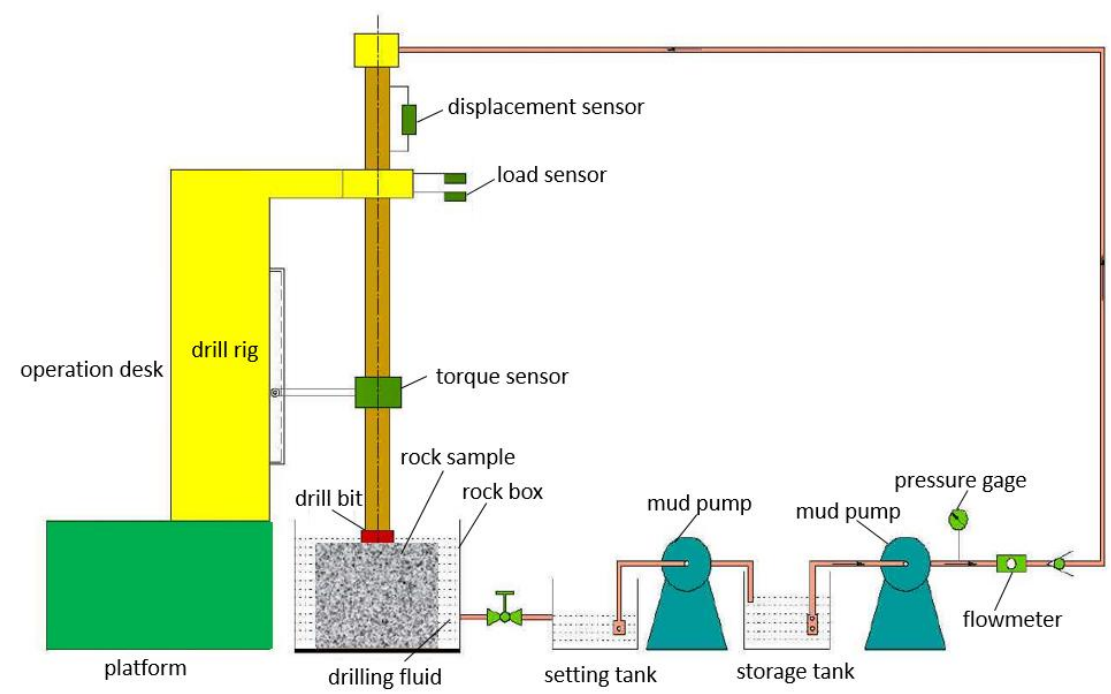

Figure 4. Schematic diagram of the polar drilling parameters testing stand.

Four types of drill bits were tested using this testing stand, including surface-set diamond bit, impregnated diamond bit, tooth-shaped diamond bit and bionic diamond bit. In addition, a torque sensor was assembled in the testing stand to measure the real-time torque, which could obtain the torque parameters with different kinds of drill bits. In the testing, three different drilling loads with $3 \mathrm{kN}, 4 \mathrm{kN}$ and $5 \mathrm{kN}$ were tested, which were simulated in the actual drilling load range provided by the cable-suspended drill [17-21]. Figure 5 shows the testing results.

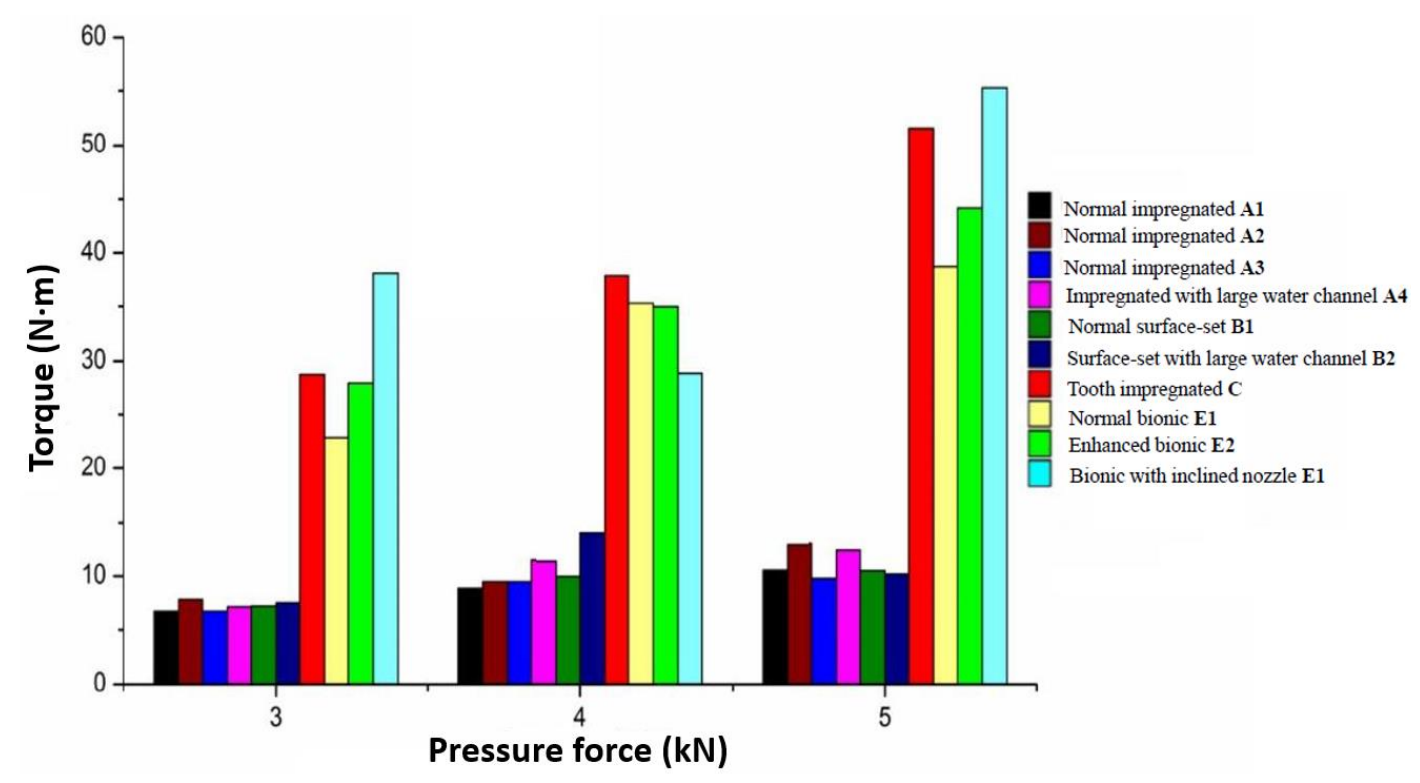

Figure 5. Relationships between the average torque and drilling pressure force with different drill bits. 
The testing results showed that when the drilling load was less than $4 \mathrm{kN}$, the drilling torques of all kinds of drill bit were less than $40 \mathrm{~N} \cdot \mathrm{m}$, while the drilling load of IBED was designed to be less than $4 \mathrm{~N} \cdot \mathrm{m}$, which means the maximum screwing torque of the drill was lower than $40 \mathrm{~N} \cdot \mathrm{m}$.

Therefore, the clamping torque should be no less than $48.7 \mathrm{~N} \cdot \mathrm{m}$ according to the drilling capacity, while the clamping torque according to the real drilling torque should be higher than $40 \mathrm{~N} \cdot \mathrm{m}$. Among the two values, the bigger one was chosen and set to integer, with a safety factor values 2.0. Finally, the required clamping torque of clamper was value-estimated as $100 \mathrm{~N} \cdot \mathrm{m}$.

\subsection{Clamping Force of the Clamper}

Conventional clampers contain two main functions: to balance the unscrew torque when disassembling the drill screw joints, and to provide a suspension force to balance the drill body weight. According to the feature of a cable-suspended electromechanical drill, the self-weight of the drill is balanced by the armored cable. Therefore, the clamping force of the clamper only needs to overcome the unscrewing torque of drill. Under conditions that the friction coefficient between the chuck jaw and the drill is constant, the clamping torque will increase in proportional to increasing of the clamping force. The larger the clamping force, the larger the clamping torque could be provided, and the same applies conversely with a smaller clamping force. Therefore, it is necessary to analyze the force conditions of the clamper, when the clamper holds the drill. Figure 6 shows the stress analysis diagram after chuck jaws tightly clamped the drill pipe.

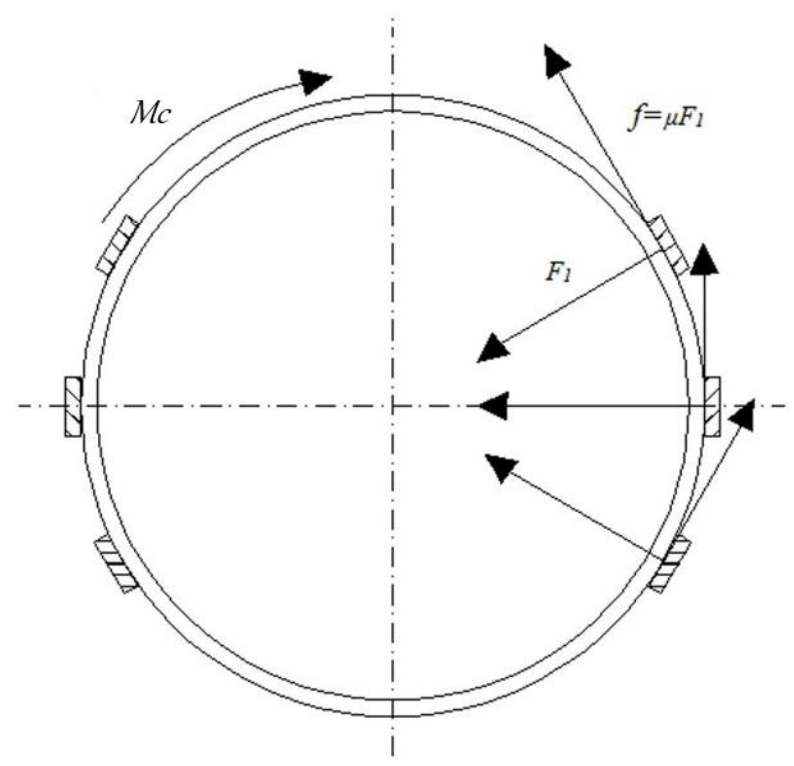

Figure 6. Diagram of force analysis under the clamping action.

Assuming that the clamping force required to overcome the torque of unscrewing the drill on each chuck jaw is $F_{1}$, according to the formula of dynamic friction:

$$
f=\mu F_{1}
$$

and the formula of torque:

$$
M_{C}=\frac{n f d}{2}
$$

Combine Equations (5) and (6) and $F_{1}$ can be obtained:

$$
F_{1}=\frac{2 M_{c}}{d n \mu}
$$


where $M_{c}$ is the clamping torque provided by the clamper, $N \cdot \mathrm{m} ; d$ is diameter of the drilling tool, $\mathrm{m}$; $n$ is the number of frictions between chuck jaw and drill pipe; and $\mu$ is the friction coefficient between chuck jaw and drill pipe.

According to the calculation in Section 3.1, the clamping torque required by the clamper is $100 \mathrm{~N} \cdot \mathrm{m}$. The drill pipe is built by stainless steel 304, and the outer diameter is $127 \mathrm{~mm}$. There are three hard alloy blocks inlaid in each two semicircle chuck jaws, so the number of frictions between chuck jaw and drill pipe is 6 . According to the research of Tian et al., when the contact pressure between chuck jaws and drill pipe is larger than $300 \mathrm{MPa}$, the friction coefficient between the chuck jaws and drill pipe can be as high as 0.9 [22], while according to the research on the equivalent friction coefficient of the single tooth theory of Zhang et al., the friction coefficient of the embedded chuck jaw is about 1.1-2 [23]. The chuck jaw is built by hard alloy material and processed interlaced surface structure, therefore, the $\mu$ was assumed to be 1.2 for calculation.

Bring the above parameters into Equation (7), $F_{1}$ values $218 \mathrm{~N}$.

There are three hard alloy blocks inlaid in each semicircle chuck jaws; therefore, the clamping force from the clamper is three times of $F_{1}$, which is $650 \mathrm{~N}$.

\section{Mechanism Design of Clamper and Control System}

According to the parameters of clamping force after calculation, the mechanical design and the motor type selection of the IBED were carried out. The designed clamper adopts the motor to drive the lead screw rotation through the gear reducer mechanism to realize the clamping and loosening actions. Figure 7 shows the mechanical structure of the clamper.

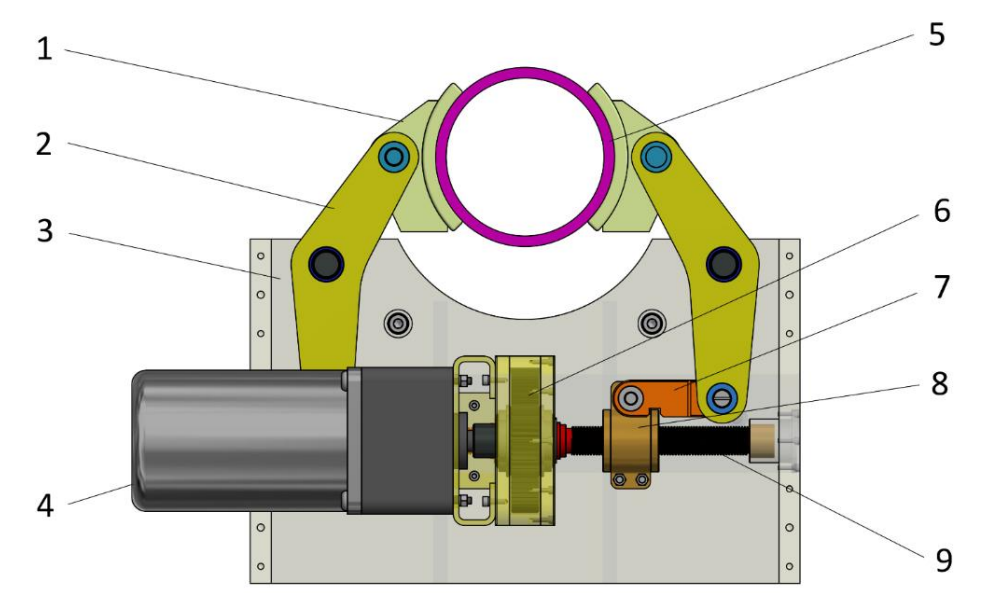

Figure 7. Structural schematic diagram of the clamper. (1—chuck jaw; 2 -swing arm; 3-shell; 4-direct current (DC) motor; 5-drill pipe; 6-reducer; 7—connecting rod; 8-travelling nut; 9-lead screw).

Due to the advantages of direct current (DC) motors, such as constant torque output, small size, and low power consumption, a DC geared motor was selected as the power source of the clamper. This DC-geared motor included a brushless permanent magnet DC motor and a gear reducer with a deceleration ration of 10:1. The motor parameters are shown in Table 1. According to the selected electric motor and the parameters of clamping force after calculation, the gear reducer box and screw were calculated and the strength checked. Finally, a straight tooth gear reducer with deceleration ratio of 1:2:4 and a single-line trapezoid thread with pitch of $2 \mathrm{~mm}$ were selected as the transmission parts.

Table 1. Parameters of the DC reduction motor.

\begin{tabular}{ccccccc}
\hline Model & Power (W) & $\begin{array}{c}\text { Rotation Speed } \\
\text { of Motor }(\mathbf{r p m})\end{array}$ & Voltage (V) & Current (A) & $\begin{array}{c}\text { Reduction } \\
\text { Ratio }\end{array}$ & $\begin{array}{c}\text { Maximum } \\
\text { Torque (N.m) }\end{array}$ \\
\hline GDM-15SC-10K & 200 & 1800 & 24 & 13.9 & 10 & 8.572 \\
\hline
\end{tabular}


The IBED pipe is made of stainless steel 304, which is relatively soft and easy to deform and damage under the action of large external forces. In order to ensure that the chuck jaws can effectively clamp the drill but will not deform the drill pipe under excessive clamping force, a current control system of the clamper was designed and developed. When the DC motor drives the chuck jaws clamping the drill pipe, the output torque of motor instantaneously increases. At the same time, the corresponding current rises sharply, which means the current of motor will increases with the motor output torque and the chuck jaw clamping force, simultaneously. Therefore, the clamping force can be controlled by current adjustment of the DC motor. With this method, we proposed and built the control system for the drill pipe clamper, which can make the chamber produce enough clamping force but will not destroy the pipe surface. Figure 8 shows the electrical schematic diagram of the control system, and Figure 9 shows system structure and electrical distribution.

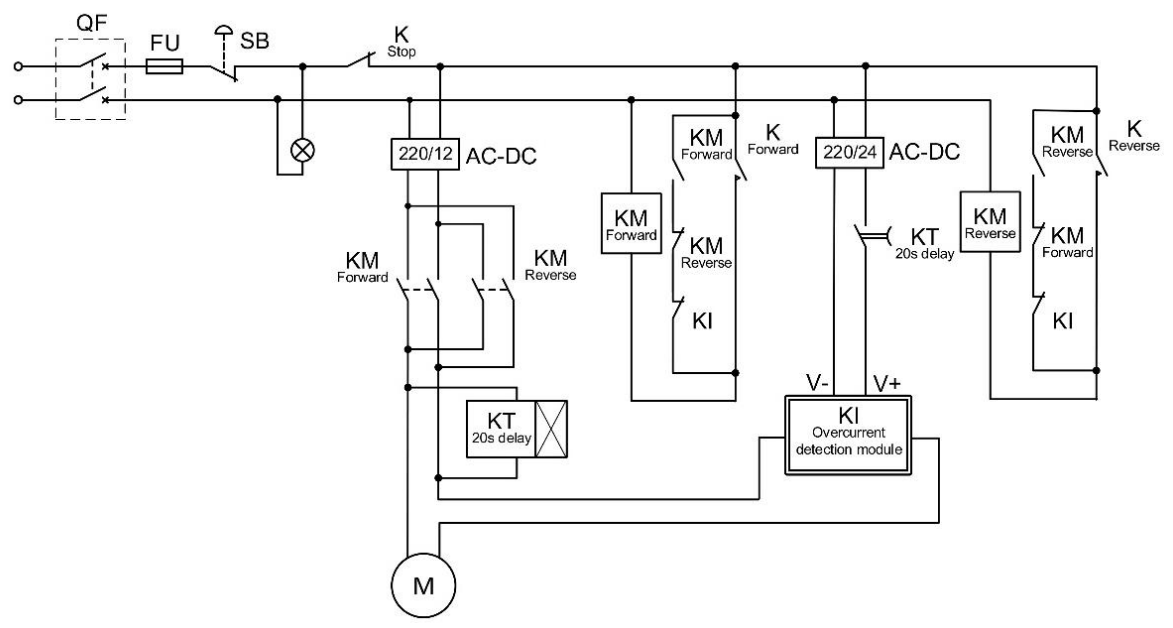

Figure 8. Electrical schematic diagram of the clamper.
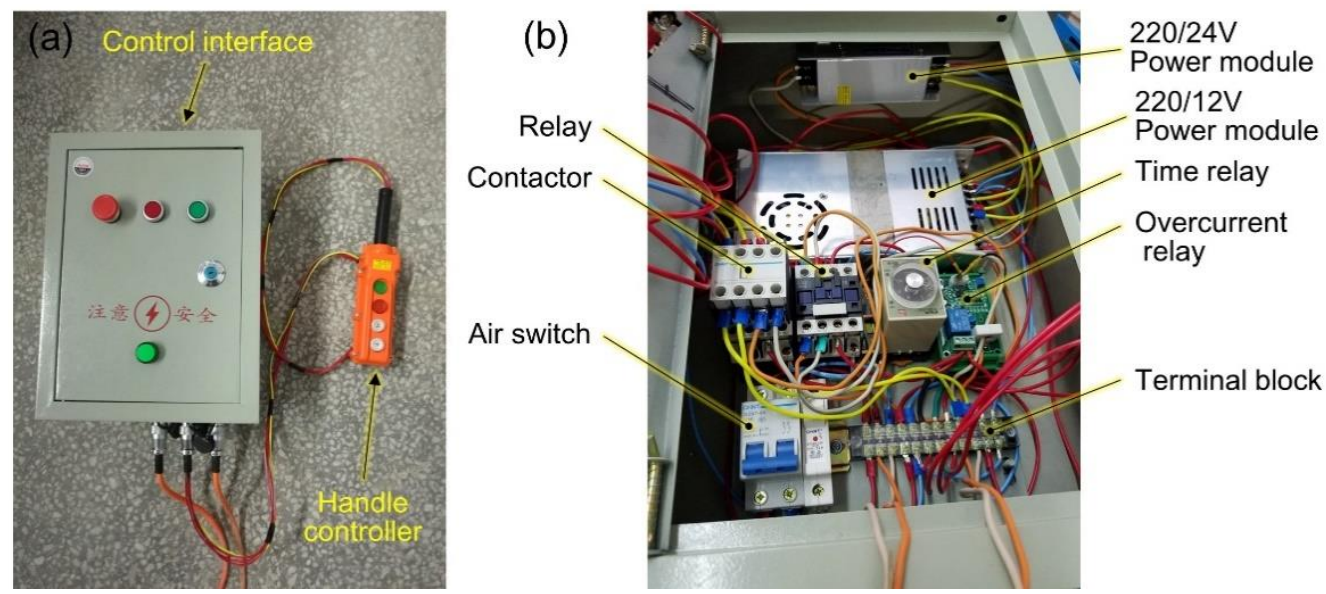

Figure 9. (a) Control interface and handle controller and (b) internal electrical structure.

The control system of the clamper includes a contactor, an air switch, a time relay, an overcurrent relay, a terminal block and two power modules which can transform $220 \mathrm{~V}$ voltage into $24 \mathrm{~V}$ and $12 \mathrm{~V}$, respectively. With the exception of the two power switches fixed on the control box interface, a handle controller is set outside of control box for more convenient controlling operations.

A current acquisition module was used as the designed control system to detect the current of the DC motor. When the current of the DC motor is larger than the set value, the control system would cut off the power supply of the DC motor and make the clamper stop the clamping action. Meanwhile, the clamping force between the chuck jaws and the drill pipe could be kept constant due to the self-locking effect of the lead screw. When the clamper is released, the lead screw drives the sliding 
nuts to move inward until the moving nuts touch the lead screw end surfaces; meanwhile, the end surface hinder the nuts continue moving and the motor current increases sharply. When the current increases to the set value, the motor stops and the clamper completes the releasing action. The above current control method could realize the automatic control of clamping and loosening action of the clamper, which greatly reduces the working risk of the clamper and avoids the possibility of accidents caused by human error.

\section{Finite Element Simulation and Analysis}

From the working principle of the clamper (Figure 3), at the moment chuck jaw holds the drill pipe, all transmission parts will be loaded, and the output torque of the DC reduction motor transforms to the clamping force between chuck jaw and drill pipe.

During the design process, all parts of the mechanical transmission chain can be designed or chosen base on the strength requirements except of non-standard parts which include: chuck jaws, swing arms and the connecting rods (Figure 10). Therefore, we carried out finite element simulation and analysis of the transmission chain consisted of nonstandard parts.

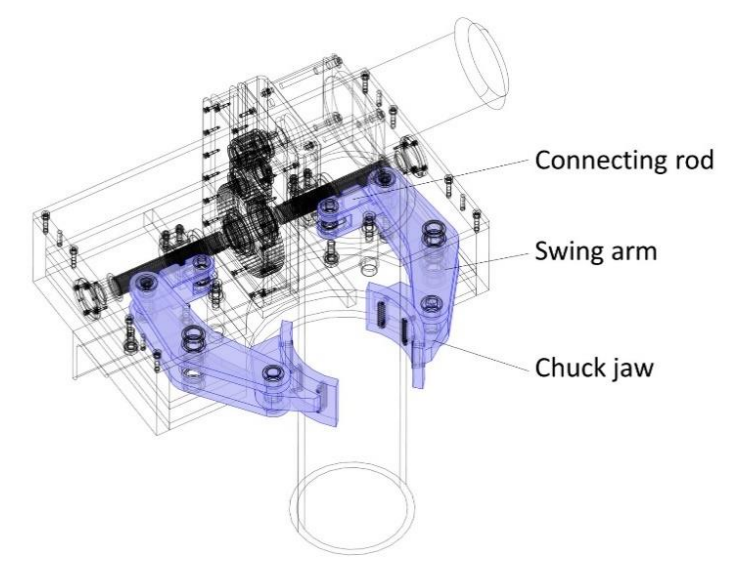

Figure 10. Mechanical transmission chain consisting of non-standard parts.

\subsection{Boundary Condition}

Based on the power transmission chain shows in the Figure 3, the maximum push force from sliding nut on the pushing block can be derived from following formula [24]:

$$
F_{\text {max }}=\frac{2 \pi M_{g \max 0} \eta_{s}}{p}
$$

where $M_{g \max 0}$ is the single side maximum output torque frim gear box, $\mathrm{N} \cdot \mathrm{m} ; \eta_{s}$ is the transmission efficiency of the sliding screw; $p$ is the screw pitch of the lead screw, $\mathrm{m}$. The $M_{g \max 0}$ can be derived from formula [25]:

$$
M_{g \max 0}=\frac{M_{D C \max } n_{i p} \eta_{g b}}{2 n_{o p}}
$$

where $M_{D C \text { max }}$ is the maximum output torque of the $200 \mathrm{~W} D C$ reduction motor, $\mathrm{N} \cdot \mathrm{m} ; n_{i p}$ and $n_{o p}$ are input and output rotation speed respectively, $\mathrm{r} / \mathrm{min} ; \eta_{g b}$ is the transmission efficiency of the gear box.

In this design, lead screw pitch is $2 \mathrm{~mm}$ and the maximum torque of the DC reduction motor is $8.572 \mathrm{~N} \cdot \mathrm{m}$. Transmission efficiency of the gear box and rectangular sliding screw usually in the range of $0.88-0.92$ and $0.3-0.6$, respectively. We assume the transmission efficiencies can reach to the maximum value under the ultimate load conditions. Therefore, bring the above parameters into Equations (8) and (9), the maximum push force loads the connecting rod can be derived as the value of 29,730.42 N, approaches to $30 \mathrm{kN}$. Boundary condition and meshing of the non-standard transmission chain are shown in Figure 11: assuming the groove areas as the fixed constraint where the chuck jaw contacts the 
standard clamp tooth; using a fixed rigid hinge constraint as the fixed pin at the middle of swing arm, and using two rigid movable hinge constrains as the two movable shared pin; applying $30 \mathrm{kN}$ force on the two half cylinder area as the push force transmit from the traveling nut.

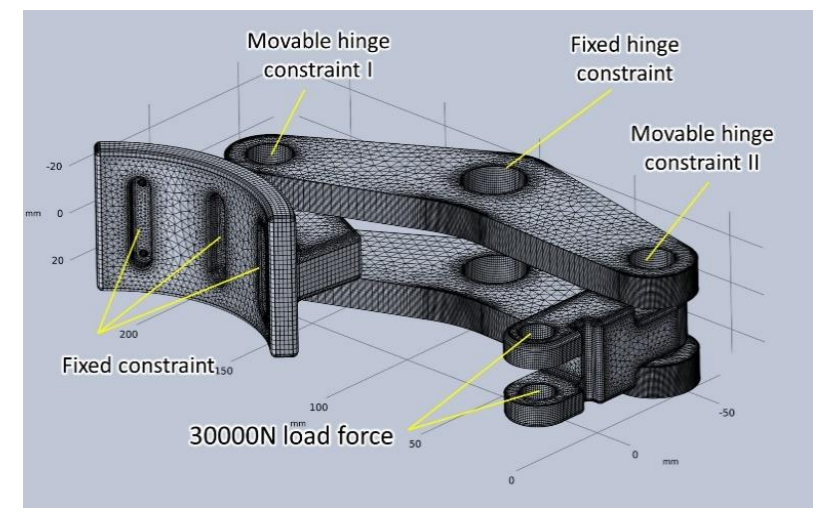

Figure 11. Boundary condition and meshing of the non-standard transmission chain.

The components of transmission chain are designed with material 40Cr (ISO 41Cr4 steel) which is well known as low temperature steel. Structural and mechanical parameters show in Table 2.

Table 2. Structural and mechanical parameters of the $40 \mathrm{Cr}$ steel.

\begin{tabular}{ccccc}
\hline Density $\left(\mathbf{k g} / \mathbf{m}^{\mathbf{3}}\right)$ & $\begin{array}{c}\text { Young Modulus } \\
\mathbf{( G P a )}\end{array}$ & Poisson Ratio & $\begin{array}{c}\text { Yield Strength } \\
\mathbf{( M P a )}\end{array}$ & $\begin{array}{c}\text { Tensile Strength } \\
\text { (MPa) }\end{array}$ \\
\hline 7850 & 209 & 0.3 & 785 & 810 \\
\hline
\end{tabular}

\subsection{Deformation Trend and Stress Distribution}

Figure 12 shows the deformation (scale factor 20) trend and Von Mises body stress distribution of the non-standard transmission chain model under $30 \mathrm{kN}$ force load. The stress concentration areas of the subparts are: middle groove area of the chuck jaw where clamp tooth installs, the inner obtuse area of swing arm and the grooving area of the connecting rod (Figure 13). The maximum Von Mises stress is $473 \mathrm{Mpa}$, which is lower than the yield strength of $40 \mathrm{Cr}$ steel and happens in the inner obtuse area of the swing arm.
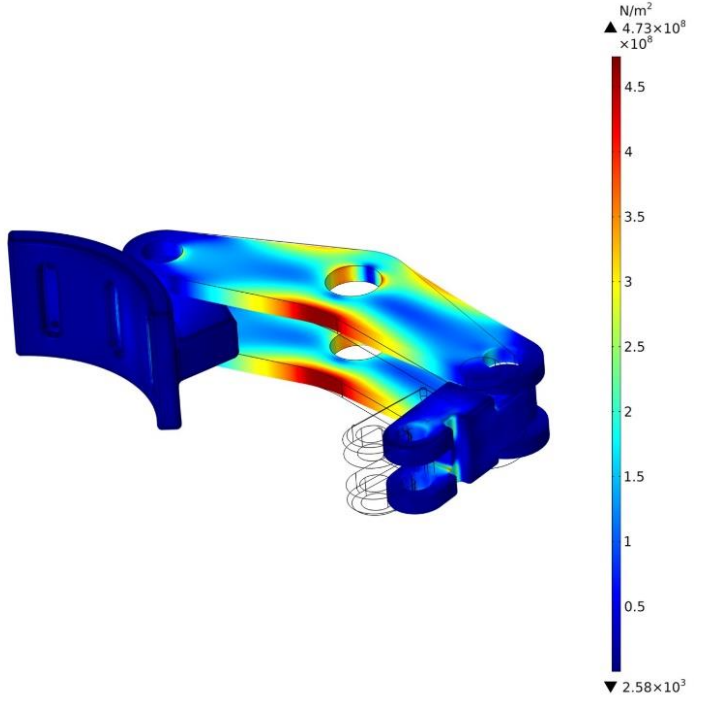
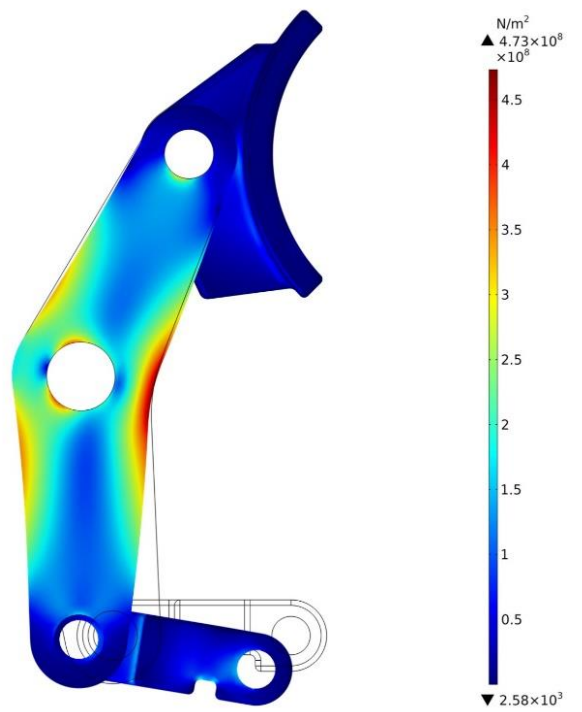

Figure 12. Deformation trend and Von Mises body stress distribution of the non-standard transmission chain model. 


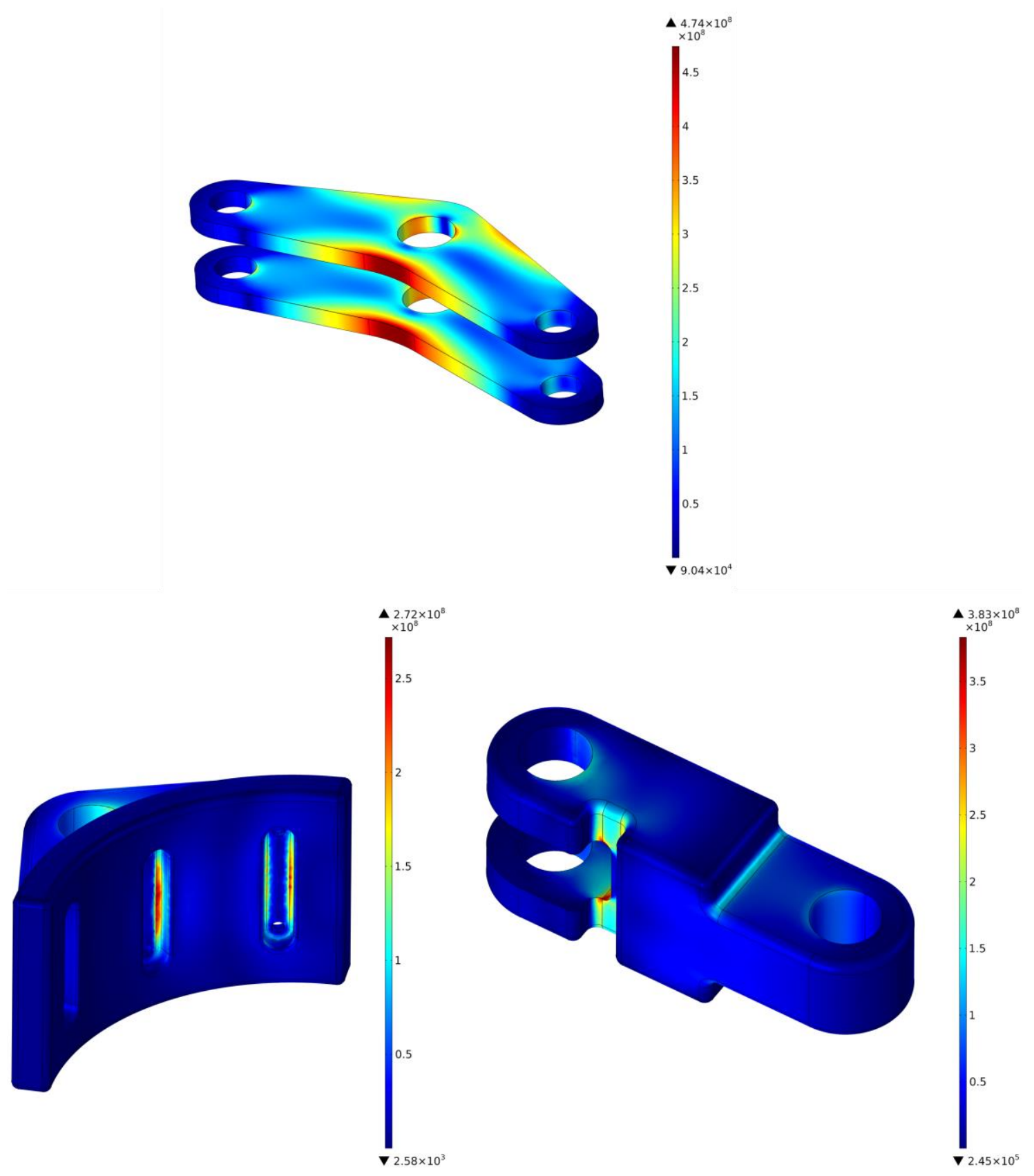

Figure 13. Von Mises body stress concentration areas of the subparts.

In this model, the thickness of the single swing arm is set as $8 \mathrm{~mm}$. To check the stress sensitivity of the subparts in the transmission chain, load force parametric scanning is added on their stress concentration edges (Figures 14-16), which are shown in the Von Mises body stress diagram (Figure 15).

In the edge Von Mises curves diagrams above, the maximum value growth rate with load force of the single swing arm is higher than the chuck jaw and connecting rod. It means that, for the three subparts made by the same material, the swing arm will reach to the yield limit strength before the other two if the load force keeps increasing. In order to make the whole transmission chain work under the safety factor values 2.0, the swing arm structure needs to be optimized. 

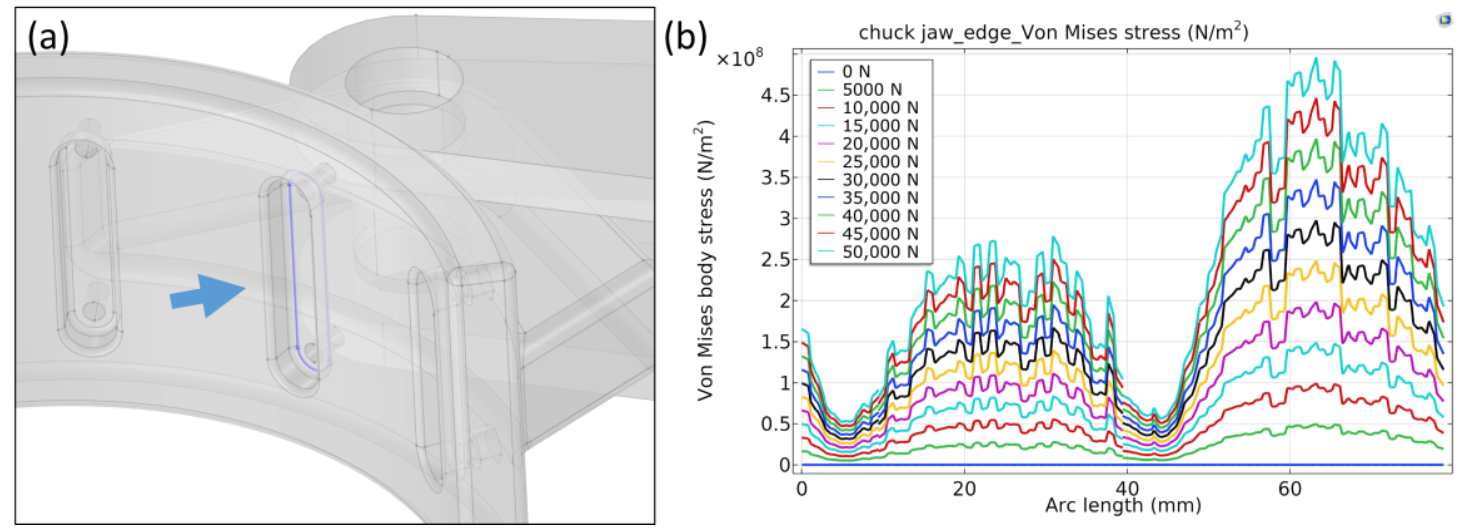

Figure 14. Load force parametric scanning of the chuck jaw: (a) edge position, and (b) Von Mises curves.
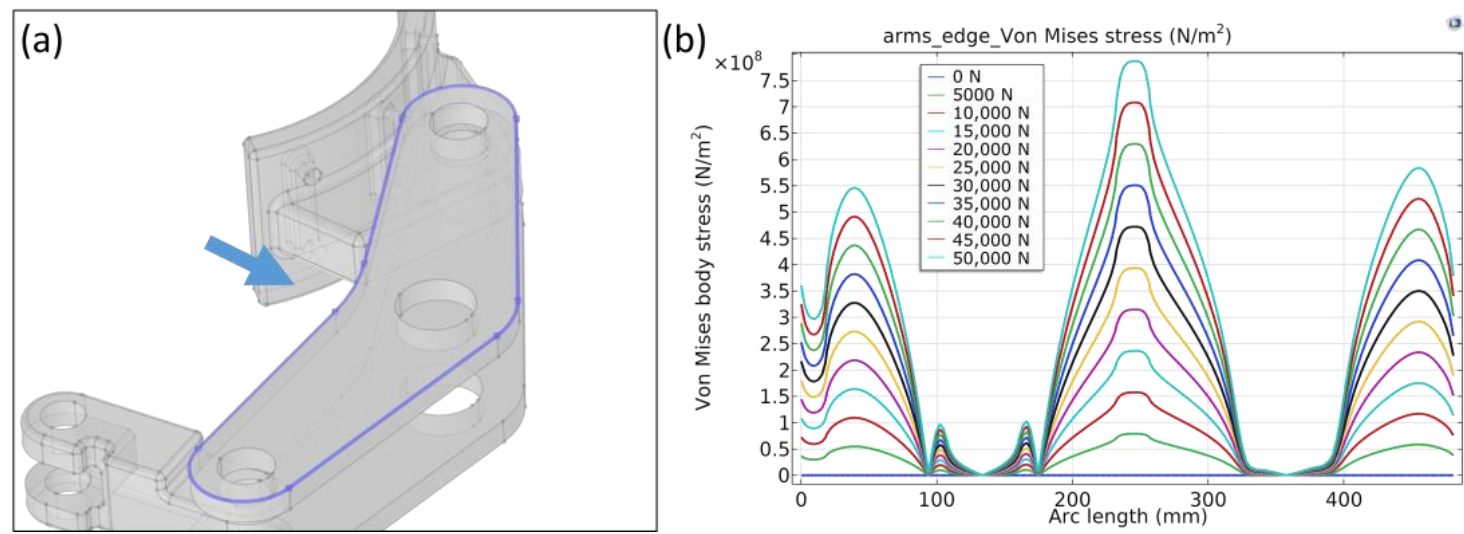

Figure 15. Load force parametric scanning of the single swing arm: (a) edge position, and (b) Von Mises curves.
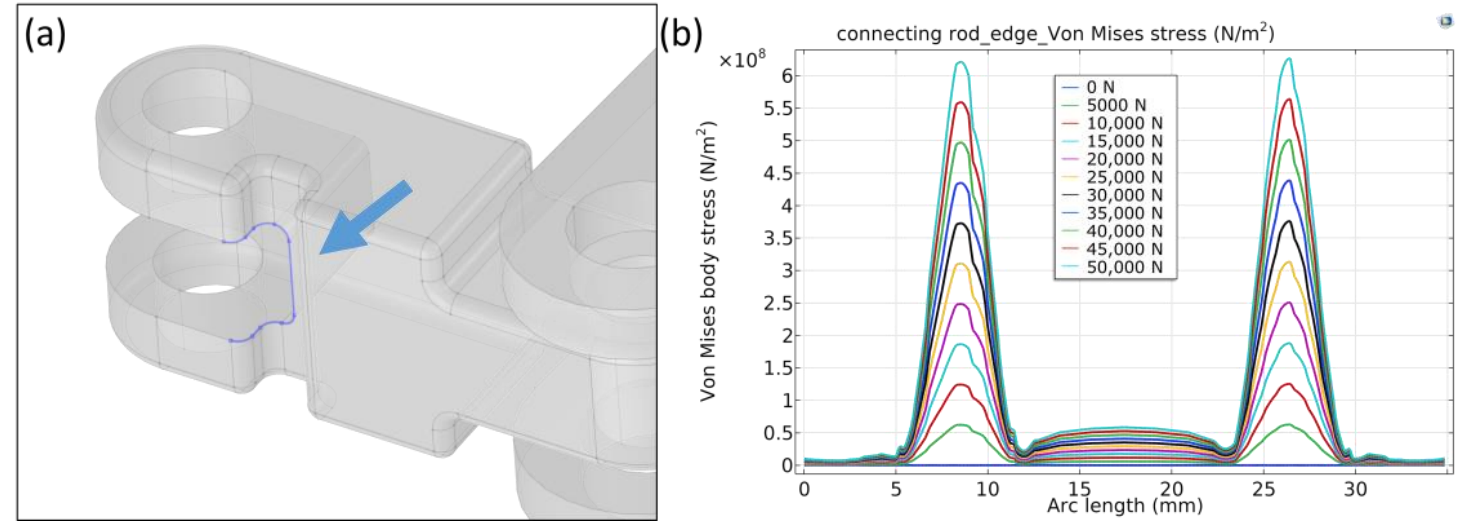

Figure 16. Load force parametric scanning of the connecting rod: (a) edge position and (b) Von Mises curves.

\subsection{Structural Optimization of the Swing Arm}

Under the $30 \mathrm{kN}$ force loading condition, if the safety factor values 2.0, the maximum Von Mises stress value on the swing arm should lower than half of the $40 \mathrm{Cr}$ material yield strength ( $392.5 \mathrm{MPa})$. Transmission chain models are built with different swing arm thickness under load force values $30 \mathrm{kN}$, and relative curves are obtained in Figure 17.

Surely, in real working conditions, the 200 W DC motor generally works under the 'non-full-power' condition with the overcurrent relay in the control interface. Nonetheless, it is meaningful to design the clamper subparts shares the similar safety factor value. Therefore, we choose $10 \mathrm{~mm}$ as the arm thickness which size can keeps the whole non-standard chain works under safety factor values 2.0. 


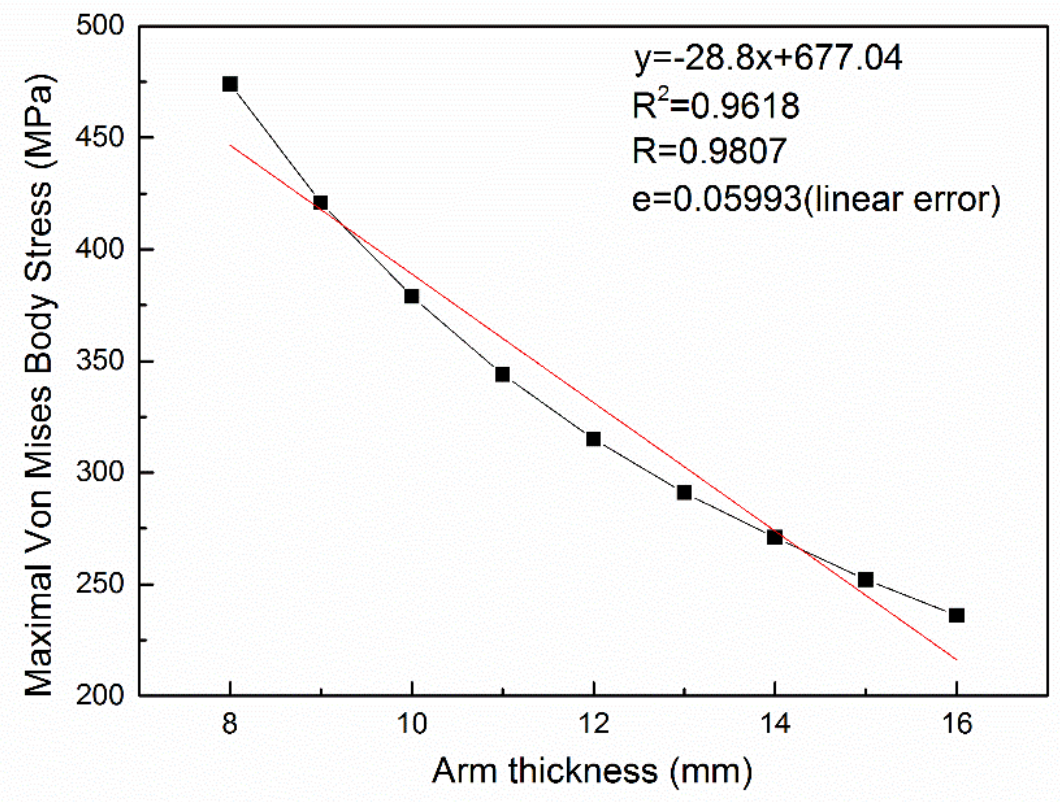

Figure 17. Maximum Von Mises stress variation tendency with different swing arm thicknesses.

\section{Clamping Force and Torque Test of Clamper}

Aims of the laboratory experiments were: (1) to explore the relationships between DC motor input current and the clamping force, clamping torque provided by the clamper; and (2) to provide a reasonable current upper limit value for the overcurrent relay setting. Therefore, a specific test stand for the clamper was designed and built.

\subsection{Clamping Force Test of Clamper}

An S-type tension-pressure sensor was used to measure the clamping force. In order to measure the maximum clamping force provided by the clamper, a polytef-made guide ring was custom designed. The pressure sensor was embedded in the guide ring: in this way, the S-type sensor was held in the direction of the maximum diameter of the semi-circular chuck jaws every time, and the two ends of the pressure sensor were slightly larger than the outer diameter of the guide ring. Figure 18 is the testing process of the clamping force. When the clamper held the guide ring tightly, the chuck jaws contact both ends of the pressure sensor slowly under the round shape guiding of the guide ring. In the meantime, the pressure increases until the clamper motor current reaches to the upper limit value and then the clamping action is stopped. During the experiment, the changing curve between the clamping force and current could be obtained by setting different current limit values.

Experimental results showed that: when the current setting was lower than $4 \mathrm{~A}$, the clamper motor could not start due to the transmission power loss of the lead screw, the gear reducer, and other factors. When the current was higher than $12 \mathrm{~A}$, the clamper motor would stop due to overload, which meant that the purpose of controlling could not be achieved. Therefore, the current value of the clamper should be within the range of 4-12 A. Figure 19 shows that the clamping force increases linearly with the increase of current, and the average clamping force ranges $219-402 \mathrm{~N}$. 


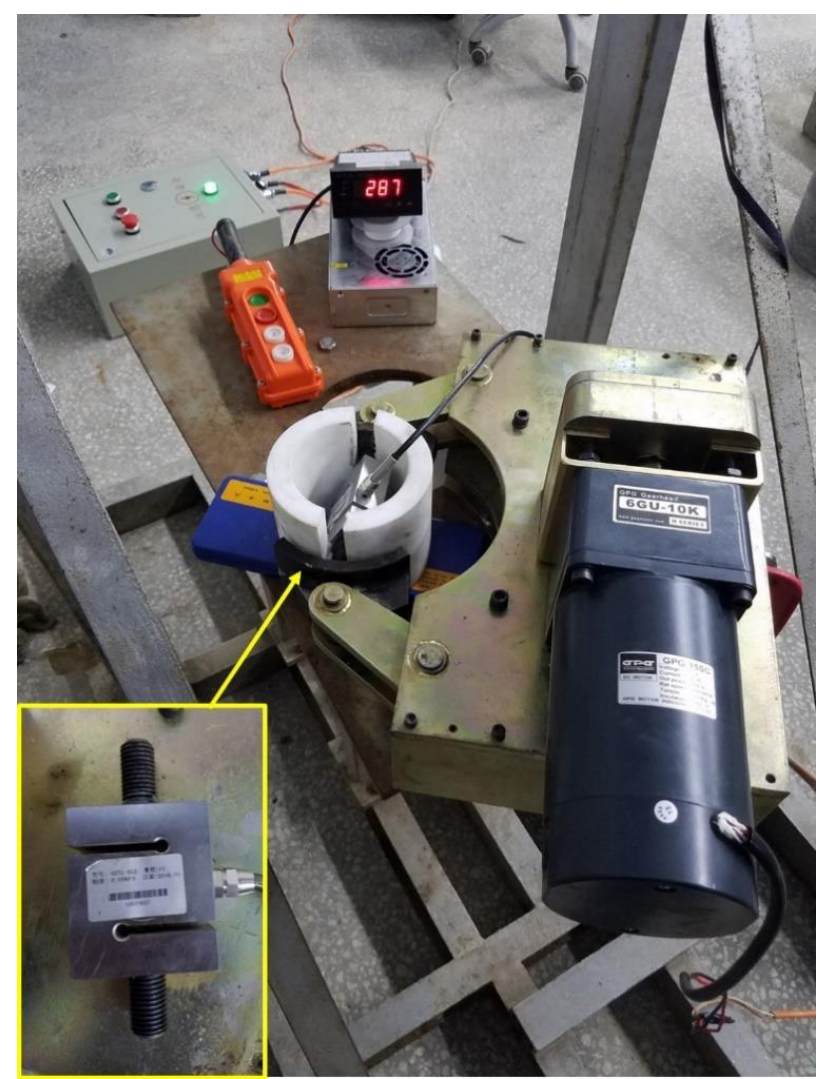

Figure 18. Clamping force testing experiment and the S-type tension tension-pressure sensor.

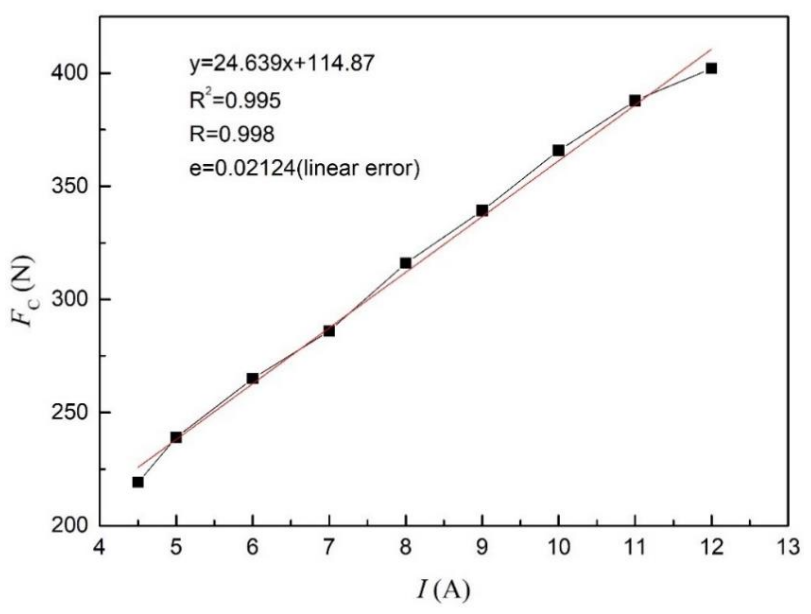

Figure 19. Curve of the clamping force with current.

\subsection{Clamping Torque Test of Clamper}

The anti-torque system testing stand of the Polar Research Center of Jilin University was improved to test the clamping torque of the clamper. The testing stand was mainly composed by torque detection system and rotating parts (Figure 20). In this experiment, the upper part of the drill pipe was connected with the rotating part through an universal joint, and the lower part of the drill pipe was placed in the central position of the chuck jaws of the clamper, while the clamper was fixed on the base of the experimental platform. After the chuck jaws clamped the drill pipe with the given current value, manually rotated the rocking bar on the top of test stand. The rocking bar would drive the drill pipe to rotate through rotating components. The torque data generated between the drill tool and the clamper 
chuck jaws were measured by the torque sensor, and the torque signal output was recorded on the upper computer in real time.
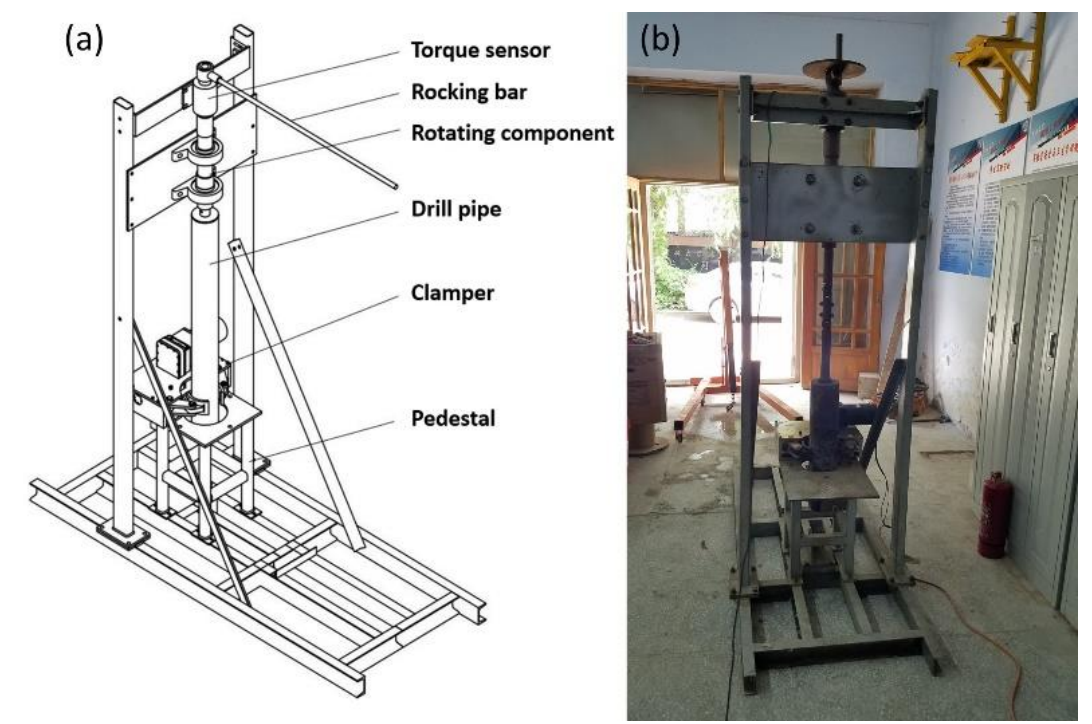

Figure 20. Clamping torque test stand: (a) structural schematic diagram and (b) appearance photo.

The torque generated when the drill pipe rotated relatively to the chuck jaws was identified as the maximum clamping torque provided by the clamper. When the upper limit of current set by the clamper was within the range of 4-12 A, the maximum clamping torque could be provided by the testing stand. The experimental data are shown in Figure 21. It can be seen that the maximum clamping torque increased with the increase of current, and this presented a linear relationship. The maximum clamping torque ranged 56-123 N.m, which could meet the requirements of the IBED [26-31].

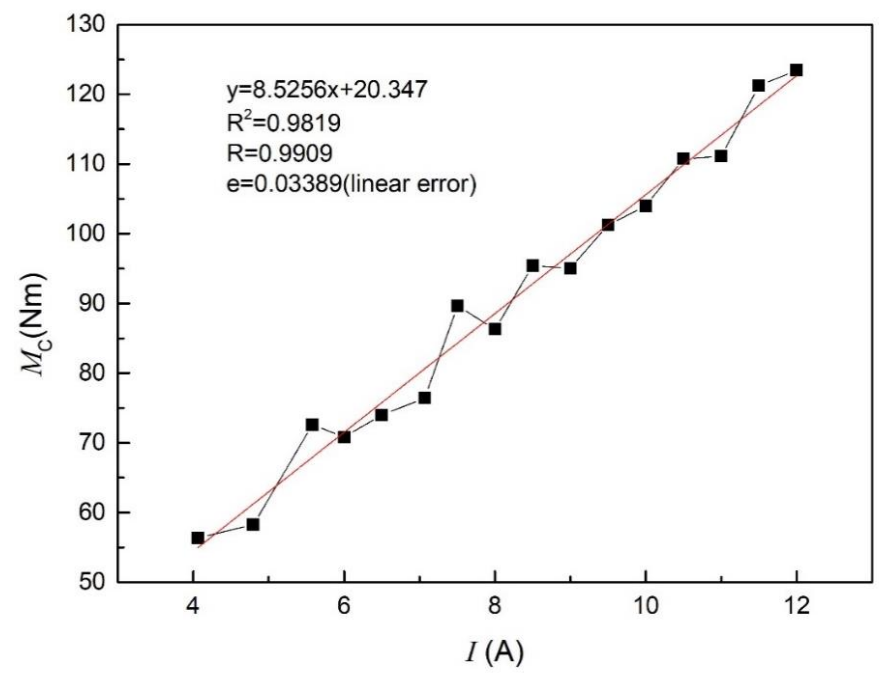

Figure 21. Changing curve of the maximum clamping torque with current.

After inputting the above experimental data of the clamping force and the maximum clamping torque into Equation (7) for calculation, the equivalent friction coefficient between the hard alloy chuck jaw and stainless-steel drill pipe was obtained, with an average value of 2.21, as shown in Table 3. It can be seen from the table that the friction coefficient actually obtained was larger than the value selected in the theoretical calculation. The probable reason was that this drill pipe was made by stainless steel, for which hardness is lower than the conventional geological drill pipes. Therefore, the hard alloy chuck jaws would forcibly be inserted into the outer surface of the stainless-steel drill pipe at a depth 
under a certain clamping force. When the drill pipe relatively rotated with the static chuck jaws, the input torque needed to overcome the frictional resistance between the two parts and the plastic damage of the drill pipe surface. This is the reason that the equivalent friction coefficient in Table 3 is larger than the theoretical calculation value.

Table 3. The equivalent friction coefficient between the hard alloy chuck jaws and stainless-steel pipe.

\begin{tabular}{ccccc}
\hline I (A) & $\mathbf{F ~ ( N )}$ & $\mathbf{M}(\mathbf{N} \cdot \mathbf{m})$ & $\boldsymbol{\mu}$ & $\bar{\mu}$ \\
\hline $4-4.5$ & 219 & 56 & 2.08 & \\
5 & 239 & 73 & 2.40 & \\
6 & 265 & 71 & 2.11 & \\
7 & 286 & 76 & 2.09 & \\
8 & 316 & 86 & 2.14 & 2.21 \\
9 & 339 & 95 & 2.21 & \\
10 & 366 & 104 & 2.24 & \\
11 & 388 & 111 & 2.25 & \\
12 & 402 & 123 & 2.41 & \\
\hline
\end{tabular}

\section{Conclusions}

(1) The theoretical clamping torque was calculated and a value of $100 \mathrm{~N} \cdot \mathrm{m}$ was chosen, according to the technical parameters of IBED ice drill and bedrock drill, with safety factor values 2.0.

(2) Finite element simulation and analysis of the non-standard transmission chain showed the mechanical reliability of the subparts, and the optimized structure of the swing arm.

(3) Considering the special natural environment at the South Pole and the size requirements of the clamper installed inside the removable drilling shelter, the clamper was designed using a DC motor to drive the clamping and loosening action of the chuck jaws through the lead screw, and automatic control of the clamping force was realized using current control, which is simple in structure, with less vulnerable parts, and easy to operate.

(4) The experimental results showed the range of clamping force and clamping torque of the clamper. In the meantime, the clamping force and clamping torque increase with the increase of the current and present a linear relationship. They can meet the clamping needs of the IBED for screwing, unscrewing and clamping, which would be greatly helpful when it is tested in field.

(5) The chuck jaw designed in this paper was a groove staggered hard alloy chuck jaw. The equivalent friction coefficient between the chuck jaws and the stainless-steel pipe is 2.21, which can meet the practical application needs. However, during the clamping process, some damage would be caused to the drill pipe. Therefore, the next step should be to optimize the shape of the groove on the surface of the chuck jaw to find the most optimal type of chuck jaw which not only can meet the requirements but also protect the external pipe of the drill to the maximum extent.

Author Contributions: This review paper was finished by P.T., X.L. (Xingchen Li), D.G., X.F., N.Z., Y.Y., Y.L. (Yongwen Liu), Y.L. (Yunchen Liu), T.W. and X.L. (Xiao Li). The statements of author contributions are as following: conceptualization, D.G., X.L. (Xingchen Li) and P.T.; methodology, D.G., X.F. and P.T.; software, X.L. (Xingchen Li) and D.G.; validation, X.L. (Xingchen Li), X.F., D.G. and P.G.; formal analysis, X.L. (Xingchen Li), D.G. and P.T.; investigation, D.G., X.F., X.L. (Xingchen Li), B.L., Y.Y., Y.L. (Yunchen Liu), X.L. (Xiao Li), N.Z. and P.T.; resources, D.G., X.L. (Xingchen Li), X.F., N.Z., Y.Y., Y.L. (Yongwen Liu), Y.L. (Yunchen Liu), T.W., X.L. (Xiao Li), P.T.; data curation, D.G., X.L. (Xiao Li), X.F. and P.T.; writing-original draft preparation, D.G., X.L. (Xingchen Li) and P.T.; writing-review and editing, X.F. and P.T.; visualization, D.G. and Y.Y.; project administration, P.T.

Funding: This research was funded by National Science Foundation of China (Project No. 41327804, 41706214, and 41506216).

Acknowledgments: The authors thank the postgraduate students of the Polar Research Center of Jilin University for their hardwork in testing the clamper and conducting other tests.

Conflicts of Interest: The authors declare no conflict of interest. 


\section{References}

1. Xiao, C.; Li, Y.; Hou, S.; Allison, I.; Bian, L.; Ren, J. Preliminary evidence indicating Dome A (Antarctica) satisfying preconditions for drilling the oldest ice core. Chin. Sci. Bull. 2008, 53, 102-106. [CrossRef]

2. Bo, S.; Siegert, M.J.; Mudd, S.M.; Sugden, D.; Fujita, S.; Xiangbin, C.; Yunyun, J.; Xueyuan, T.; Yuansheng, L. The Gamburtsev mountains and the origin and early evolution of the Antarctic Ice Sheet. Nature 2009, 459, 690-693. [CrossRef]

3. Talalay, P.G. Exploration of Gamburtsev Subglacial Mountains, East Antarctica: Background and plans for the near future. Geogr. Environ. Sustain. 2014, 7, 5-15. [CrossRef]

4. Anderson, E.J.; Fujisaki-Manome, A.; Kessler, J.; Lang, G.; Chu, P.; Kelley, J.; Chen, Y.; Wang, J. Ice Forecasting in the Next-Generation Great Lakes Operational Forecast System (GLOFS). J. Mar. Sci. Eng. 2018, 6, 123. [CrossRef]

5. Creyts, T.T.; Ferraccioli, F.; Bell, R.E.; Wolovick, M.; Corr, H.; Rose, K.C.; Frearson, N.; Damaske, D.; Jordan, T.; Braaten, D.; et al. Freezing of ridges and water networks preserves the Gamburtsev Subglacial Mountains for millions of years. Geophys. Res. Lett. 2014, 41, 8114-8122. [CrossRef]

6. Steig, E.J.; Morse, D.L.; Waddington, E.D.; Stuiver, M.; Grootes, P.M.; Mayewski, P.A.; Twickler, M.S.; Whitlow, S.I. Wisconsinan and Holocene climate history from an ice core at Taylor Dome, western Ross Embayment, Antarctica. Geogr. Ann. 2000, 82, 213-235. [CrossRef]

7. Slangen, A.; van de Wal, R.; Reerink, T.; de Winter, R.; Hunter, J.; Woodworth, P.; Edwards, T. The Impact of Uncertainties in Ice Sheet Dynamics on Sea-Level Allowances at Tide Gauge Locations. J. Mar. Sci. Eng. 2017, 5, 21. [CrossRef]

8. Saliba, F.M.; Cardoso, M.; Torres, M.F.; Teixeira, A.C.; Lourenço, E.J.V.; Telles, D.D.M. A rationale method for evaluating unscrewing torque values of prosthetic screws in dental implants. J. Appl. Oral Sci. Rev. Fob 2011, 19, 63. [CrossRef]

9. Talalay, P.G. Subglacial till and bedrock drilling. Cold Reg. Sci. Technol. 2013, 86, 142-166. [CrossRef]

10. Zapol, W.M. Future Science Opportunities in Antarctica and the Southern Ocean; The National Academies Press: Washington, DC, USA, 2011.

11. Zhou, X.; Walker, P.; Zhang, N.; Zhu, B.; Ruan, J. Numerical and experimental investigation of drag torque in a two-speed dual clutch transmission. Mech. Mach. Theory 2014, 79, 46-63. [CrossRef]

12. Triest, J.; Mulvaney, R.; Alemany, O. Technical innovation sand optimizations for intermediate ice-core drilling operations. Ann. Glaciol. 2014, 55, 243-252. [CrossRef]

13. Gao, J.; Yan, G.; He, S.; Xu, F.; Wang, Z. Design, analysis, and testing of a motor-driven capsule robot based on a sliding clamper. Robotica 2017, 35, 521-536. [CrossRef]

14. Azuma, N.; Tanabe, I.; Motoyama, H. Heat generated by cutting ice in deep ice-core drilling. Ann. Glaciol. 2007, 47, 61-67. [CrossRef]

15. Zhang, N.; An, C.; Fan, X.; Shi, G.; Li, C.; Liu, J.; Hu, Z.; Talalay, P.; Sun, Y.; Li, Y. Chinese first deep ice-core drilling project DK-1 at Dome A, Antarctica (2011-2013): Progress and performance. Ann. Glaciol. 2014, 55, 65-71. [CrossRef]

16. Cao, P.; Yang, C.; Chen, Y.; Chen, B.; Talalay, P. Experimental study of the drilling process in debris-rich ice. Cold Reg. Sci. Technol. 2015, 120, 138-144. [CrossRef]

17. Fan, X. Research on the Balance between Subglacial Bedrock Drilling Parameters and Capabilities of Antitorque System of Cable-Suspended Electromechanical Drill; Jilin University: Changchun, China, 2014.

18. Cao, P.; Chen, B.; Liu, C.; Yang, C.; Talalay, P. Experimental investigation of cutting temperature in ice drilling. Cold Reg. Sci. Technol. 2015, 116, 78-85. [CrossRef]

19. Augustin, L.; Panichi, S.; Frascati, F. EPICA Dome C 2 drilling operation: Performances, difficulties, results. Ann. Glaciol. 2007, 47, 68-72. [CrossRef]

20. Talalay, P.; Fan, X.; Zheng, Z.; Xue, J.; Cao, P.; Zhang, N.; Wang, R.; Yu, D.; Yu, C.; Zhang, Y.; et al. Anti-torque systems of electromechanical cable-suspended drills and test results. Ann. Glaciol. 2014, 55, $207-218$. [CrossRef]

21. Ueda, H.T.; Garfield, D.E. Core Drilling through the Antarctic Ice Sheet; Technical Report 231; CRREL: Hanover, NH, USA, 1969; pp. 1-17.

22. Tian, H.; Hu, S. Experimental study on frictional factor between chuck jaw and drilling rod. Coal Geol. Explor. 2003, 31. 
23. Zhang, Y.; Wang, Y.; Wang, D. Experimental study on tooth shape design of drill pipe chuck jaws. Pet. Mach. 1981, 9, 1-17. (In Chinese)

24. Heya, A.; Nakata, Y.; Sakai, M.; Ishiguro, H.; Hirata, K. Force Estimation Method for a Magnetic Lead-Screw-Driven Linear Actuator. IEEE Trans. Magn. 2018, 54, 8207805. [CrossRef]

25. Gonçalves, D.E.; Fernandes, C.M.; Martins, R.C.; Seabra, J.H. Torque loss in a gearbox lubricated with wind turbine gear oils. Lubr. Sci. 2013, 25, 297-311. [CrossRef]

26. Cao, P.; Yang, C.; Zheng, Z.; Wang, R.; Zhang, N.; Liu, C.; Hu, Z.; Talalay, P. Low-load diamond drill bits for subglacial bedrock sampling. Ann. Glaciol. 2014, 55, 124-130. [CrossRef]

27. Talalay, P.G. Power consumption of deep ice electromechanical drills. Cold Reg. Sci. Technol. 2003, 37, 69-79. [CrossRef]

28. Herber, T.U.; John, K. Experiments on the Cutting Process in Ice; Report 89-5; CRREL: Hanover, NH, USA, 1989.

29. Shamshev, F.A.; Tarakanov, S.N.; Kudryashov, B.B.; Pariiskii, Y.N.; Yakovlev, A.M.; Sal'e, E.A. Technology and Technique of prospecting drilling. Mosc. Nedra 1985, 565. (In Russian)

30. Wumkes, M.A. Development of the U.S. deep coring ice drill. Mem. Natl. Inst. Polar Res. 1994, 49, 41-51.

31. Wehrle, E. A shallow core-collecting mechanical ice drill. Anare Res. Notes 1985, 28, 196-201.

(C) 2019 by the authors. Licensee MDPI, Basel, Switzerland. This article is an open access article distributed under the terms and conditions of the Creative Commons Attribution (CC BY) license (http://creativecommons.org/licenses/by/4.0/). 